\title{
An Analysis on the Language Style of the Utterances in Magnum Advertisements
}

\author{
Sonia Niken Permatasari \\ Made Frida Yulia \\ English Language Education Study Program \\ Sanata Dharma University
}

\begin{abstract}
The role of broadcasted advertisements is undeniably important for the companies to market their products. To convince the audience, advertisers have to convey the persuasive message through the use of linguistic features. Those linguistic features will influence the persuasion techniques used in advertisements and the power relation which is built between the companies and the consumers.

This study attempted to solve two research problems related to the language style of the utterances in Magnum advertisements. They were (1) What are the linguistic features of Magnum advertisements? (2) What kind of power relation does Magnum have upon consumers through the advertisements?

As an endeavor to solve those two problems, document analysis was employed in analyzing the transcript of the utterances in ten (10) Magnum advertisements. The first research problem was solved by categorizing the words or the sentences into some linguistic features of advertising language proposed by Grey (2008). The second research problem was solved by interpreting the power relation in Magnum advertisements based on French's and Raven's theory (1959).

From the obtained data, it was found that there were only a few linguistic features which appeared in Magnum advertisements. The power relation between the companies and the consumers could be defined easily because the utterances were clear enough. Furthermore, the simplicity of Magnum advertisements presented Magnum's special characteristics albeit the advertisers did not vary the language style.
\end{abstract}

Keywords: language style, advertisement, Magnum, linguistic features, power relation

\section{A. INTRODUCTION}

Every company needs media to disseminate their products to people, the consumers of their products. Advertisements become the most well-known mass media because many companies use advertisements for particular aims. Gilson and Berkman (1986) define advertisements as the persuasive media of communication to help companies achieve marketing objectives. To meet this need, companies should make the best advertisement with the most suitable language style.
Asher (1994) states that advertising language is used to persuade or to tempt people to buy companies' products. It means that advertisements use persuasive language to entice consumers. Advertisers should know what kind of persuasive language which is suitable for certain products and make consumers believe in the companies' products. According to Grey (2008), to convey the persuasive message of advertisements, advertisers often use some linguistic features, such as hyperbole, repetition, glamorization, and some syntactic features, such as short 
sentences, long noun phrases, and ambiguity. Therefore, diction will be a very crucial thing in advertisements to grab the audience's attention. Since broadcasted advertisements can be seen and heard, an utterance is as important as the visualization. Utterances hold important points because the audience can easily notice the uttered words instead of the written one.

Every product has a big deal with people's perspective about product brands, there are some power relation which are built by companies upon consumers through advertisements. According to Peirce (1886), power relation is the power which is built from the message sender to the message receiver through the communication act. This power is created by advertisers to build the brand image in society. French and Raven (1959) classify power relation into five types, namely reward power, expert power, legitimate power, referent power, and coercive power.

Based on Magnum's official website (2012), "Magnum was the first handheld ice cream targeted as a premium ice cream for adults. Today, Magnum is one of the world's leading ice cream brands, selling one billion units annually worldwide, and it is the biggest brand of Unilever ice creams." It is true that Magnum is a product which has a great success in marketing its product to people all around the world. This success is also influenced by the use of mass media to spread the existence of all products from Magnum. Considering Magnum's success in marketing its products, the researchers would like to analyze the language style which is used in Magnum advertisements. The problems are formulated into the following questions: (1) What are the linguistic features of Magnum advertisements? and (2) What kind of power relation does Magnum have upon consumers through the advertisements?

\section{B. METHODOLOGY}

To answer the two research questions, document analysis was employed. Leedy and Ormrod (2005: 142) define content analysis as "a detailed and systematic examination of the contents of a particular body of material for the purpose of identifying patterns, themes, or biases." It means that content analysis allows the analyst to analyze information from certain data sources in order to describe particular characteristics of the information. In this research, the data sources were ten (10) videos of Magnum advertisements, namely Magnum Mini version, Magnum Ecuador version, Magnum Infinity version, Magnum Classic version, Magnum Temptation version, Magnum Temptation Hazelnut version, Selecta Magnum version, Magnum advertisement in 1994, Magnum advertisement in 1993, and Magnum advertisement in 1992.

To answer the first research question, related to the use of certain linguistic features of advertisements, Grey's theory (2008) was used to analyze the language style of advertising. It was chosen because there is specific description on the characteristics of advertisement language. For the second research question, the theory of power relation proposed by French and Raven (1959) was employed. The utterances in Magnum advertisements were analyzed and classified into the types of power relation.

\section{THEORETICAL GROUND AND DISCUSSION}

There are two parts in this section. The first part discusses the linguistic features of Magnum advertisements. The second part explains the kinds of power relation in Magnum advertisements.

\section{The Linguistic Features of Magnum Advertisements}

Based on Grey (2008), there are two major features of the advertisement language 
style. They are lexical features and syntactic features. Magnum advertisements had some parts of those elements in the language they used to grab the consumers' attention.

a. The Lexical Features of Magnum Advertisements

The lexical features of Magnum advertisements deal with the diction used in advertisements. In this case, the words were spoken by the actors, actresses, and the narrators of Magnum advertisements. The diction can empower people to believe what the speakers say in the advertisements upon the advertised products. It was found that Magnum advertisements only had some lexical features of the advertising language. They lacked neologism, repetition, and humor. The result of the data analysis dealing with the lexical features of Magnum advertisements can be seen in Figure 1.

Figure 1 The Lexical Features of Magnum Advertisements

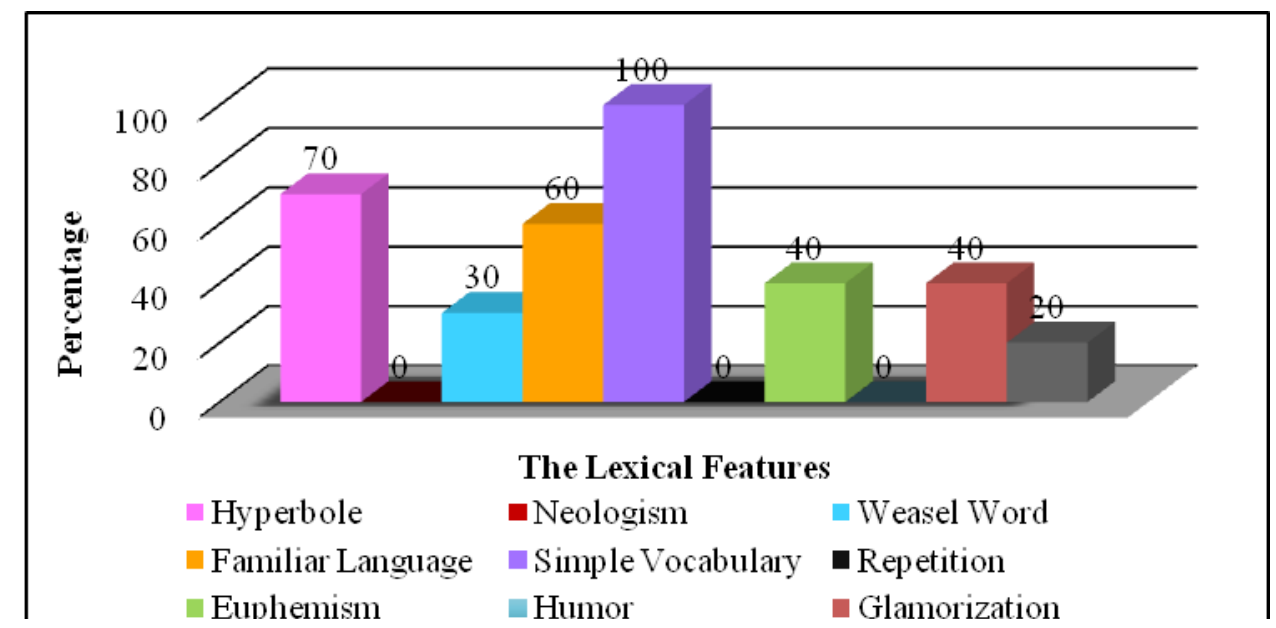

Simplicity in the advertisement diction makes people easy to remember what is said by the speakers. The vocabulary will be universal because the advertisers will not consider who will be the audience. The slogan of Magnum, for pleasure seekers, was a simple slogan which emphasized who would be the consumers of Magnum. That slogan meant that the consumers should be a person who was looking for the pleasure. That person could find the pleasure by consuming Magnum. It was understandable without any ambiguity because the vocabulary was very simple, brief, and clear.

Leech (1972) argues that hyperbole is often concerned with personal values and sentiments. Hyperbole is one way to exaggerate the product in order to attract the consumers' attention to the product. There were seven Magnum advertisements which had the hyperbole feature in the advertisements. The advertisement of Magnum Infinity had the highest number of occurrences. For example, the use of longer lasting pleasure described how the consumers could feel the longer pleasure when they ate Magnum Infinity than other ice cream. The word new dominated the hyperbole feature in Magnum advertisements, such as New Magnum Ecuador and New Magnum Temptation. It showed that the advertisers emphasized the presence of the new Magnum product in the midst of Magnum advertisements. Besides, the phrase for the first time also had the same meaning as the word new. Other words which indicated the use of hyperbole in Magnum advertisements were special, intense, forever, perfection, very, and best. The presence of hyperbole in Magnum advertisements added the variation 
of personal expression which could affect the consumers' willingness to taste Magnum whether the speakers' utterances were true.

The word you indicates familiar language in the advertisements. It creates more friendly attitudes between the companies and the consumers. Grey (2008) states that the use of such apronoun makes the audience feel involved within the advertisement. There were $60 \%$ of Magnum advertisements which clearly used the pronoun you to address the consumers. The narrator in Magnum Classic advertisement said, "When you are having a magnum with thick cracking chocolate, nothing else matters" The pronoun you in that utterance pointed out the consumers as if the narrator were talking to them.

Based on Grey's explanation (2008), euphemism is a type of figurative language which carries connotative meaning. This figurative language appeared in $40 \%$ of Magnum advertisements. The word ecstasy in 1994 Magnum advertisement indicated how Magnum could make people want to eat it again and again as they were consuming ecstasy. The actress compared Magnum with ecstasy to describe the continual pleasure they wanted to get after consuming those two different things. The connotative meaning carried by the speakers of Magnum advertisements were shown in the words indulgence, cruel, talk, and slide. They viewed Magnum like other things which had the same quality. Euphemisms could be used to give ideas about what Magnum tastes like.

Glamorization oftenuses uncommon word combination in order to create more interesting phrases. The words employed in advertisements are modified in such a way by combining the words which are uncommonly used in daily speaking. It is one way to give glamorization touch in advertisements. Glamorization could be found in four Magnum advertisements.
Cracking chocolate was one of the popular characteristics of Magnum advertisements. The word crack was identical to earthquake, egg, and many more but not to ice cream because people knew that ice cream was not tough. In Magnum advertisements, the word cracking often modified the word chocolate to describe the sound which people would hear when they were biting the chocolate. In Magnum Temptation advertisement, the speaker said that the chocolate of Magnum is the delicious browny pieces to create glamorization. Another glamorization could be seen in shacked cracking chocolate and reunion ice cream.

Grey (2008) states that a weasel word carries unspecified meaning. Therefore, it makes people question the missing information. There were only three Magnum advertisements which used weasel word to gain the consumers' attention. In the advertisement of Magnum in 1992, the actress said that Magnum was so different. People could ask a question "from what it is different." Then, it affected people's curiosity to find out from what aspect it is different by buying the product. The phrase another little indulgence in Magnum Mini advertisement also could make people curious about what kind of indulgence it is and decide to buy the advertised product.

Grey (2008) argues that potential words are those which are able to give new value or novelty.Potency appeared in two Magnum advertisements. In the advertisement of Magnum Temptation, the word for the first time in "Magnum presented for the first time" was an example of the use of potency. People could draw a conclusion that Magnum had a new product to the market. Similar to it, the word again and again in Magnum Mini advertisement was also a potential word. Those words showed that Magnum Mini was an ice cream which made people want to consume for many times. 
Magnum advertisements did not have the features of neologism, repetition, and humor. Magnum advertisements did not introduce a new word which was formed by joining two or more word parts. Moreover, repetition rarely appeared in the utterances of the advertisements because it was often used in written form. The way of delivering message done by the advertisers did not present humor to make the advertisements more attractive because they focused on the description of the products in a serious atmosphere at the matter of utterances.

\section{b. The Syntactic Features of Magnum Advertisements}

Different from lexical features which give the view of extraordinary products through the diction, syntactic features can show how simple the advertisement language style should be. Syntactic features deal with grammatical properties. The result of the analysis of the syntactic features of Magnum advertisements could be described in Figure 2.

Figure 2 The Syntactic Features of Magnum Advertisements

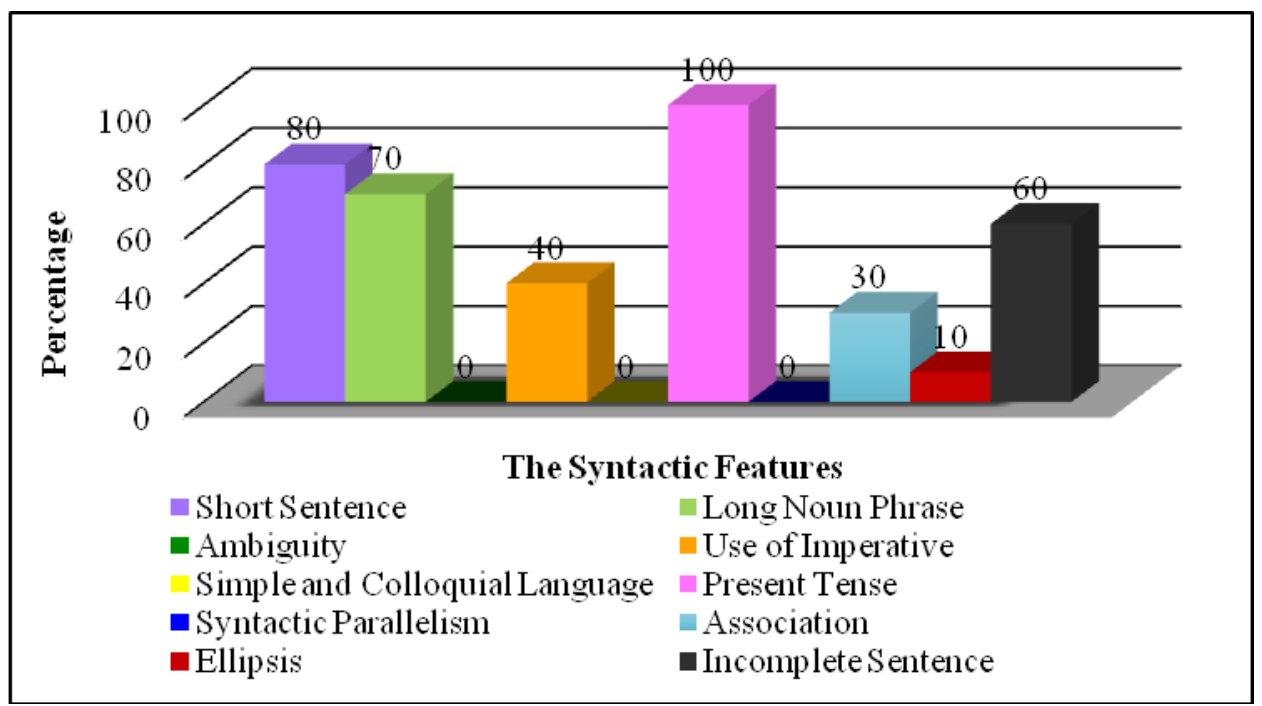

Grey (2008) states that present tense verbs could give a pictorial of the real situation whenever the audience hears the advertisements. All Magnum advertisements used present tenses in the speakers' utterances. A few parts of the actors' and the actresses' utterances in the two old versions of Magnum advertisements in 1993 and 1994 used a simple future tense, a simple past tense, and a future perfect tense but the majority of the utterances still used present tense. Magnum advertisement in 1994 showed the actress who said the sentences which used the simple present tense and future perfect tense, as in "Magnum is bliss.
You're luxury. My special moment. I would've been my own." "Magnum is bliss" and "You're luxury" were the examples of the simple present tense sentences and "I would've been my own" was the example of a future perfect tense sentence.

A short sentence is easier to understand for the audience because they sometimes only hear or do not really listen carefully to the utterances spoken by the speakers in the advertisements. A short sentence usually indicates the use of simple sentence which is the preferable pattern on delivering the advertisement message to the audience. There were eight Magnum 
advertisements which had this feature. All actors and actresses stated very short sentences. In Magnum advertisement in 1994, a woman said, "Nothing compares to Magnum." That sentence only had a subject, a verb, and an object and could be identified as a short sentence.

Grey (2008) states that a long noun phrase requires at least three words or two independent phrases. A long noun phrase has the function to convince the consumers that the advertised product has many specialties. There were $70 \%$ of Magnum advertisements which had long noun phrases in their utterances. They consisted of three words in the majority. In Selecta Magnum advertisement, there were two long noun phrases, international ice cream sensation and thick rich Belgium chocolate. Most of the long noun phrases in Magnum advertisements described how the ice cream was, how the chocolate quality was, and how the pleasure the consumers would get when they were eating Magnum.

The audience only pays attention to the main idea of the product. Therefore, it is unnecessary for advertisers to make many complete and formal sentences in advertisements. There were $60 \%$ of Magnum advertisements which had incomplete sentences.Mostofthoseincompletesentences described the quality of Magnum itself. For example, "The new Magnum temptation with chocolate sauce where chocolate delicious browny pieces covered by Belgium chocolate" could be found in Magnum Temptation advertisement. Grammatically, that sentence structure was wrong because there were some missing words. It could be arranged in a complete sentence, like "There is a new Magnum temptation which is produced with chocolate sauce where you can find chocolate in the form of deliciousbrowny pieces covered by Belgium chocolate."
An imperative is a common language feature in advertisements. The advertisers ask the audience to do something by using an imperative. Only four advertisements of Magnum had this feature. The two of them were the pieces of the actor' or the actress' conversation, like "Watch this"in Magnum Infinity and "Cut the alarm"in Magnum Temptation. The narrator in Magnum Temptation Hazelnut advertisement said, "Feel the chocolates hazelnut basis of banana ice cream in covered in shacked cracking chocolate." She suggested the audience to consume Magnum. It had a similar meaning to "Grab it fast," "Buy now," or many other examples that people usually saw in common advertisements. Those imperatives were used to increase the consumers' willingness to do something related to the marketing purposes of the company.

Grey (2008) proposes that association is the way advertisers connect a positive side of a product to something elsewhich is familiar in the daily life. The use of like and $a s$ sometimes indicates the association.It is used to give dramatization and clear imagination to the audience. There were $30 \%$ of Magnum advertisements which used association, but some of them did not use the connector words, such as like and as. However, they indicated association because the speakers compared Magnum with something else. In Magnum Mini version, the narrator compared Magnum Mini with little indulgence. Similar to that, the actress in Magnum Infinity advertisement compared Magnum with cruel people. In fact, Magnum was only a delicious ice cream which they imagined as something they loved more than anything. Those two examples of association did not use the word like or as. The association which used the connector like could be found in Magnum advertisement in 1994. The speaker said, "I felt like under confession afterwards." She compared her feeling of consuming Magnum 
to the confession. She admitted that eating Magnum was like feeling guilty for herself, but she could not avoid the guilt of eating Magnum because it pleased her well.

Goddard (2002) defines ellipsis as "the omission of part of a structure." Cook (1996) says one of its aims is to create the sense of informality. Generally, ellipsis is usually used to create informality in a conversation by omitting certain parts of a structure without affecting the meaning. There was only one ellipsis which appeared in Magnum advertisements. It appeared in Magnum Ecuador advertisement. The actress said, "Sorry, guys. Sorry. Hi." The utterance "Sorry" belonged to ellipsis because it could create an informal conversation. If it had been in a formal situation, it would have been "I am sorry."

However, Magnum advertisements did not have the features of ambiguity, simple and colloquial language, and syntactical parallelism. Every utterance was clearly stated without more than one cognitive meaning because the advertisers made those utterances simple and brief.The utterances in Magnum advertisements were daily conversations which could be categorized into informal style. However, those utterances did not fit Grey's idea (2008) about a simple and colloquial language feature in Magnum advertisements.The advertisers maintained the simple concept on the use of language to quickly catch the audience's attention by avoiding the use of syntactic parallelism.

\section{THE POWER RELATION IN MAGNUM ADVERTISEMENTS}

Peirce (1886) states that power is built from the relation between message senders and message receivers. According to Petress in Triandjojo (2008), power is the capability to persuade others to believe or to do something like what is wanted. Triandjojo (2008) argues that an advertisement is an ideology reflection from a company. It can be a medium for companies to communicate with consumers. The relation which is built by companies and consumers is called power relation. Power relation makes communication act occur between companies as message senders and consumers as message receivers. French and Raven (1959) divide the types of power relation into five types, namely legitimate power, reward power, referent power, expert power, and coercive power.

Table 1 The Power Relation Used in Magnum Advertisements

\begin{tabular}{|l|c|l|}
\hline \multicolumn{1}{|c|}{ Power Relation } & Percentage & \multicolumn{1}{c|}{ Magnum Advertisements } \\
\hline Legitimate Power & 20 & $\begin{array}{l}\text { Magnum Classic } \\
\text { Magnum Temptation Hazelnut }\end{array}$ \\
\hline Reward Power & 0 & None \\
\hline Referent Power & 20 & $\begin{array}{l}\text { Magnum Mini } \\
\text { Magnum Temptation }\end{array}$ \\
\hline Expert Power & 60 & $\begin{array}{l}\text { Magnum Ecuador } \\
\text { Magnum Infinity } \\
\text { Magnum Selecta } \\
\text { Magnum advertisement in 1994 } \\
\text { Magnum advertisement in 1993 } \\
\text { Magnum advertisement in 1992 }\end{array}$ \\
\hline Coercive Power & 0 & None \\
\hline
\end{tabular}


Advertisements become a medium to present companies' thought about their product to consumers. Advertisers are the representatives of companies to send the companies' thought to consumers through advertisements. The power relation in each Magnum advertisement could be different because the idea of presenting the advertisements was also various from one to the others. Table 1 shows the analysis result of power relation in Magnum advertisements based on the utterances and the speakers.

There were only three kinds of power relation which appeared in Magnum advertisements. The majority of Magnum advertisements used the expert power to communicate the idea about Magnum.

\section{Legitimate Power}

French and Raven (1959) describe legitimate power as the power which is built when message senders are able to control message receivers. The legitimate power requires the authority of high-positionedperson to dictate people who have lower position than he does. In advertisements, companies have higher position than consumers do. Therefore, companies as message senders have the right to dictate people to do something. There were 20\% of Magnum advertisements which used the power of legitimate. The speakers of those advertisements said some sentences which indicated suggestion to the audience to do something.

In Magnum Classic advertisement, the narrator said, "When you are having a magnum with thick cracking chocolate, nothing else matters." It indicated that the narrator suggested people to have a Magnum if they wanted to feel the pleasure which could make them relaxed for a while from their business. Besides, Magnum Temptation Hazelnut advertisement had an imperative sentence spoken by the narrator. She said, "Feel the chocolate hazelnut basis of banana ice cream in covered in shacked cracking chocolate." This imperative sentence was an order to the audience. The narrator actually asked the audience to buy Magnum Temptation Hazelnut and taste it.

\section{Reward Power}

Companies can give a reward to the audience if they use the advertised product. This strategy builds the reward power between companies and consumers. That reward is usually in the form of a lottery, a product bonus, or many more. It is the most interesting power to attract people's willingness to buy the product. However, Magnum advertisements did not use this power because the company did not offer any kind of reward for the consumers.

\section{Referent Power}

Presenting famous people in the advertisement is a great idea to market a product. Popular people can influence their fans to follow their life style, such as the product they use or consume. The referent power develops admiration and a desire to be like certain popular people in advertisements. There were $20 \%$ of Magnum advertisements which had this kind of power relation. Magnum Mini advertisement presented Eva Longoria as the actress who was enjoying Magnum Mini. She was a beautiful actress who often appeared in some other Magnum advertisements. Magnum Temptation advertisement is starred by Caroline Correan and Benicio Del Toro. Those two advertisements were very attractive because the actresses and the actor could attract the audience. The referent power does not have certain language characteristics through advertisements because the main point of this power is the presence of the actor or the actress who are already well-known among the audience of Magnum advertisements.

\section{Expert Power}

An assumption of knowing everything about a product is a basic part of building the 
expert power. Companies place themselves as the ones who understand that the advertised product is highly recommended to use. Therefore, they suggest the audience to use it. In Magnum advertisements, the expert power appeared in more than a half of the advertisements. There were $60 \%$ of Magnum advertisements which built that power by telling the audience about the specialty of Magnum. The speakers described the quality of Magnum and the satisfaction which they had after they consumed Magnum.

The narrators' description about Magnum in Magnum Ecuador advertisement, Magnum Infinity advertisement, and Selecta Magnum advertisement indicated the expert power because the narrators exactly knew the main ingredients of Magnum. In Selecta Magnum advertisement, the narrator described Magnum as an international ice cream sensation with thick rich Belgium chocolate, coated by classic, almond, or in double chocolate. From the description, the audience could know the quality of Magnum which was mentioned by the narrators.

Attaching some opinions of Magnum consumers was also a way of describing Magnum and its satisfaction. It appeared in Magnum advertisement in 1994, Magnum advertisement in 1993, and Magnum advertisement in 1992. Those three advertisements showed how the consumers liked Magnum. They shared what they tasted and what they felt when they were having Magnum. A woman in Magnum advertisement in 1993 said, "When I've got a Magnum, I suddenly get very possessive. I came over my own and nothing can come to distract me. The piece I like best is one that chocolate cracks for the first time." Those sentences made the audience imagine how that woman was satisfied when she was eating Magnum.

\section{Coercive Power}

Loudon in Supriyono (2006) states that message senders can delete a promised reward if message receivers do not follow the suggestion in advertisements. If the audience as the message receiver does not do what is ordered by the message senders, the companies as the message senders can delete the promised reward or do something which is not good for the audience. This power relation is not so pleasant that many advertisers do not use it in advertisements. Magnum advertisement was one of advertisements which did not use coercive power to build the power relation between the company and the consumers.

\section{CONCLUSIONS}

Based on the discussion above, some conclusions could be drawn. The advertising language has its own uniqueness to be analyzed, especially the linguistic features which appear along advertisements and can influence the kinds of the power relation. Based on Grey's theory (2008), Magnum advertisements only had $36 \%$ of the whole lexical features and $39 \%$ of the whole syntactic features. The speakers presented simple language of advertising to advertise Magnum. Magnum advertisements did not have neologism, repetition, and humor features. They had weasel words, familiar language, euphemisms, glamorization, and potency features although they were only $50 \%$ or less. All of Magnum advertisements used simple vocabulary and most of them used hyperbole to exaggerate Magnum ice cream. For the syntactic features, Magnum advertisements lacked ambiguity, simple and colloquial language, and syntactic parallelism features. The majority of Magnum advertisements used short sentences, long noun phrases, present tense, and incomplete sentences features. The other features which they had in the minority were the use of imperatives, association, and ellipsis features. 
The theory of power relation proposed by French and Raven (1959) showed how the power between companies and consumers could be categorized into some kinds of power relation. Most magnum advertisements had the expertpower because the advertisers emphasized the product description and assume that they were the only one who knew about the product. The referent power appeared in two Magnum advertisements. They presented famous public figures to influence people to consume Magnum as what those people did. The two other Magnum advertisements built the legitimate power upon the advertisements to suggest people to do something related to the products.

In brief, Magnum advertisements' simplicityaffected the use oflinguisticfeatures in their utterances. That simplicity did not require many linguistic features of linguistic. Therefore, Magnum advertisements only had a few linguistic features. The power relation which was built between the companies and the consumers of Magnum advertisements consisted of three kinds of power relation, namely the legitimate power, the referent power, and the expert power. It dealt with how the advertisers presented the product through the advertisements.

\section{REFERENCES}

Asher, R. E. (1994). The encyclopedia of language and linguistics (Vol. 2). Oxford: Pergamon Press.

Cook, G. (1996). The discourse of advertising. London: Routledge.
French, J. R. P., \& Raven, B. (1959). The bases of social power. Ann Arbor, MI: University of Michigan Press.

Gilson, C. \& Berkman, H. (1986). Advertising, concept and strategies. Blacklick. $\mathrm{OH}$ : McGraw-Hill College.

Goddard, A. (2002). The language of advertising $\left(2^{\text {nd }}\right.$ ed.). New York: Routledge.

Grey, D. (2008). Language in use. Cambridge: Cambridge University Press.

Leech, G. N. (1972). Englishin advertising: A linguistic study of advertising in Great Britain. London: Longman.

Leedy, P. D., \& Ormrod, J. E. (2005). Practical research: Planning and design $\left(8^{\text {th }}\right.$ ed.). Upper Saddle River, NJ: Pearson Prentice Hall.

Magnum Official Website. (n.d.). About Magnum. Retrieved on October 2nd, 2012, from http://magnumicecream. com/about_us

Peirce, C. S. (1886). Writings of Charles $S$. Peirce: A chronological edition (Vol. 6). Bloomington, IN: Indiana University Press.

Supriyono, A. (2006). Power relation between producers and consumers created in English advertisement. (Unpublished master's thesis). Semarang: Semarang University.

Triandjono, I. (2008). Semiotika iklan mobil di media cetak Indonesia. (Unpublished master's thesis). Semarang: Diponegoro University. 